\section{NOTES ON THE TELEPHONE.}

BY I. L. DUERDEN .

When an iron armature approaches the poles of a permanent magnet on which insulated wire is wound, a current of electricity is thereby induced, and flows in one direction through the insulated wire; and when the armature is moved from the poles of the magnet a similar current flows through the wire, but in a reverse direction; and conversely, if the currents thus produced be passed through insulated wire wound on another permanent magnet, the armature of the second magnet will move in the same time as the first, but not necessarily in the same relative direction, as that will depend on the relative polarity of the magnets.

In the Bell telephone, the iron diaphragm which serves as an armature is caused to move directly to and from its permanent magnet, by minute concussions of air, from the speaker's throat. As these concussions are necessarily lim. ited in their ability to move the diaphragm, it follows that if the slight movement thus produced could be used to properly control a power (in the same manner as the slight movement of the slide valve of a steam engine controls the admission of steam to its cylinder), instead of directly producing it, a much more powerful telephonic result could be obtained.

With this object in view, after several experiments, $\mathrm{I}$ constructed a transmitter on the principle shown in the engraving, in which $\mathrm{A}$ represents a metal speaking tube, having a mem the sewing needle, $\mathrm{C}$ (metallically connected to the fine wire, $\mathrm{D}$, which is soldered, at $\mathrm{D}^{\prime}$, to the speaking tube, at) $D$, to the speaking tube, $\mathbf{A}$ ) is secured by sealing wax. The end, $\mathrm{C}^{\prime}$, of the needle is hooked, so as to clip the short piece of very fine platinum wire, E. One pole of the galvanic cell, $\mathrm{S}$, is connected with the metallic post, $A^{\prime}$, to which the speaking tube, $A$, is sold $A$, is soldered, whereby the end, $\mathrm{C}^{\prime}$, of the needle becomes the negative terminal of the
battery, $\mathrm{S}$; and the positive pole, $\mathrm{P}$, has two wires, $\mathrm{F}$ and $\mathrm{K}$, connected with it; the wire, $F$, leading through the telephone, M, to one end of the platinum wire, $\mathrm{E}$, and the wire $\mathrm{K}$, leading wire, $K$, leading through the telephone, $\mathrm{N}$, to the other of the wire,

By this arrangement there are two courses open to the galvanic current from the end, $C^{\prime}$, of the needle to the positive pole of the battery, $\mathrm{S}$; and when the resistance of each course is the same, the current divides itself equally between the two; but as the between the two; but as the
platinum wire, $\mathbf{E}$, has great platinum wire, E, has great resistance to the current, the
least movement, in either dileast movement, in either direction of its arrow, of the make the course towards which it moves the one of the which it moves the one of the

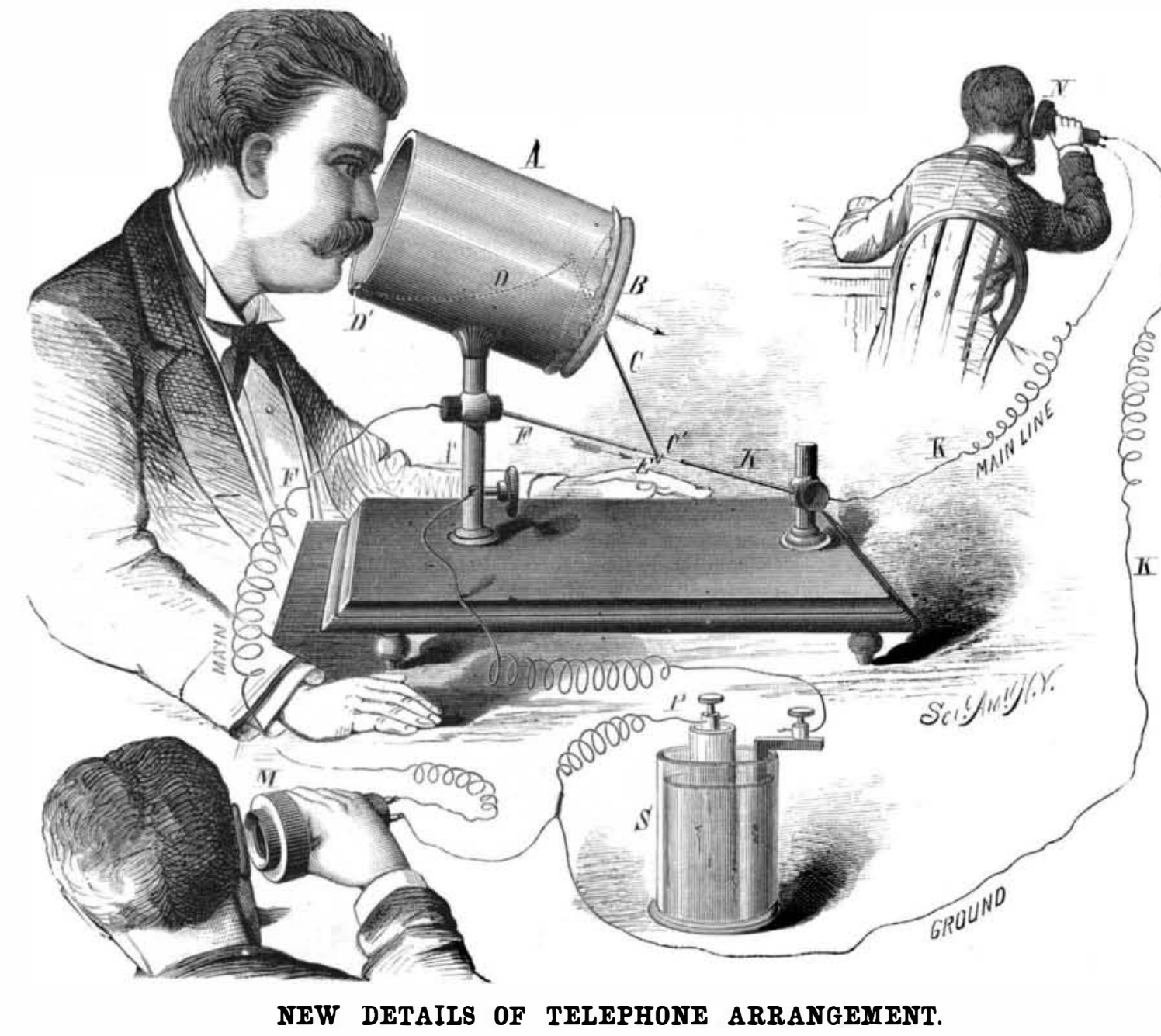

pus, in the muscular substance, lay the needle. It was sup. $\quad$ An improved Adding Machine has been invented by $\mathrm{Mr}$. posed that until loosened by suppuration the broken end of $\mathrm{W}$. W. Hopkins, of Thorntown, Ind. The elements of the the needle remained fixed in the rib, thus pinning the heart

A still more remarkable accident, with recovery, is reported in the Transactions of the Medical Society of Penn (hoint of the out at the back. The victim was swung three times into
. The the air by the rearing of the horses, then pushed himself off, hemoptysis followe with some assistance. No cough or into the pleura occurred with discharge of pus, front and back. This gradually lessened, and finally both wounds osed, the one in the breast last. The boy has recovered

\section{New Mechanical Inventions.}

An improved Link Motion has been patented by Mr. S. Hamblin, of Greenville, $\mathrm{Pa}$. The arrangement permits adjusting the link of a reversible engine by means of a cord, and also clamping the link in any desired position, so that the engine may be run with the operating valve at less than

fullstroke.
Mr. S. M. Moore, of Canastota, N. Y., has patented an $\begin{aligned} & \text { the inside by a system of worm wheel gearing operated by } \\ & \text { a crank, the mechanical devices being original and efficient. }\end{aligned}$ improved system of Manufacturing Knife Blades, by means In a Stone Sawing Machine invented by Mr. W. Tuggey, of chine are, first, two series of notched wheels bearing numbers on their periphery; second, a corresponding series of endless chains mounted on the wheels; third, a box having the nine digits and the cipher inscribed in parallel rows with the rows of digits: The several chains and rows of un correspond to the units, hundreds, and thousands colmachine is operated by moving the chains successively downward the length of the distance of each number to be added, etc.

Mr. C. E. Patterson, of Wellsboro, Pa., has invented an tween dates, price for Calculating Interest, difference beand performing various other mathematical problems. The machine is compact, being a circular box about four inche in diameter and two inches in depth. The movable parts or off two rollers.

Mr. P. C. Close, of Augusta, Ga, has invented a $B$

Mr. P. C. Close, of Augusta, Ga., has invented a Bu In a Stone Sawing Machine invented by Mr. W. Tuggey, of
West Rutland,Vt., the patentee provides improved means for perating all the gripperssimultaneously, for the purpose of releasing them from thei bite on the guide rods, so as to enable the gang of saws to enable the gang of saws
to be raised quickly when their work is done.

Mr. P. Langlois, of Port Henry, N. Y., has patented a Sewing Machine having an improved set of feeding devices adapted to secure more positive and uniform feed, and to permit the better turning of the work. A swiveling feed step-is located upon a peculiarly constructed fourmotioned feed having positive movement in every direction.

A simple Horse Power, in vented by Mr. C. E. Macarthy, of Forsyth, Ga., is made by arranging upon the vertical king post, to which the sweep is attached, a large horizontal grooved pulley, and in combining with the same an endless rope or belt, which is wrapped once around the horizontal pulley, and is then passed around a vertical speed pulley upon vertical speed pulley upon
one side of the king post, one side of the king post,
and then around a vertical tension pulley upon the other side.

Mr. J. Grubs, of Licking ville, $\mathrm{Pa}$., has invented an improved Drill Bit for drilling oil, salt, and artesian wells. In drilling such wells

movement increases the resistance of the other course; so / steel, and in such a manner that the grain of the steel, it is the usual practice has been to first run down a small bit that the relative difference in the resistance of the courses craimed, will not be injured at the junction of the bladeand (termed a "center bit"), and then enlarge the hole by means appears to be in proportion to the square of the resistance tang, thus remedying a defect common in knives produced of a reamer. This drill enables the same result to be pro-

that is thus produced by the movement of the hooked end, by hand forging. A series of peculiarly shaped dies and du $\mathrm{C}^{\prime}$, of the needle.

Now the voice of the person who is speaking at the mouth An improvement in Mill Stone Drivers, made by Mr. D. of the tube, A, causes the membrane, B, to move to and fro T. Staples, of Galt's Mills, Va., consists in connecting the in either direction of its arrow, and the length and speed driver with the stone by a collar having seats for the driver, of these movements differ as different words are uttered; which collar is located in a frame rigidly fixed in the top of \begin{tabular}{l|l} 
of these movements differ as different words are uttered; & which collar is located in a frame rigidly fixed in the top of \\
and as the needle, C, is rigidly secured to the membrane, B, & the stone, and is supported upon diametrical lugs, which en-
\end{tabular} by sealing wax, its end, $\mathrm{C}^{\prime}$, copies the length and speed of ter recesses in the frame and cause the stone to turn with the the movements of the membrane, and by like movements in driver. These lugs allow the collar to oscillate slightly, to either direction of its arrow directs a current to the wires, cause both ends of the driver to bear against the same.

$\mathrm{F}$ or K, which corresponds in power to the varying length Mr. R. D. Mossman, of Bristol, N. H., has invented an of these movements. The wire, E, should be stretched, and improved Machine for making Wood Pulp for Paper. It the hooked end, $\mathbf{C}^{\prime}$, must have an upward tendency, so as to has a grindstone in whose face there are diagonal grooves keep it in uniform contact with the wire, $E$

filled with corundum, the stone being mounted on a verti-

The instrument as above described serves simply as a cal shaft and inclosed in a curb: In opposite sides of the transmitter, and by careful adjustment at $\mathrm{C}^{\prime}$, and speaking latter are adjustable pockets for containing the wooden in an undertone, the sounds through the telephones, $\mathrm{M} \mathrm{N}$, blocks from which the paper pulp is made.

were almost articulate. Singing in an ordinary tone would A novel Steam Engine, invented by Mr. T. A. Henderson, break contact at $\mathbf{C}^{\prime}$; but the results obtained were sufficient of Natchez, Miss., is of that class of engines in which the to encourage the construction of another instrument, and if function of the steam cylinder is performed by a bellowsbetter results are obtained I shall be happy to describe it. shaped expansible and collapsible vessel. In Mr. Hender-

\section{Two Remarkable Accidentso}

son's engine there are two such vessels, provided with a slide son's engine there are two such vessels, provided with a slide
valve and suitableconnecting and operating mechanism.

In the transactions of the Medical Society of New Jersey, A convenient machine for Turning and Eyeletting Cases for 1877 , Dr. Ryerson reportsthe case of a child whichlived for umbrellas, fishing rods, etc., has been patented by Mr. four weeks with over an inch of No. 1 sewing needle in W. Harnah, of New York city. A hollow cone, heated by the heart. Search for the needle before death was unsuccess- a warm water circulation so as to soften the material, rethrough the cartilage of the found to have passed partially ceives the cases, wrong side out. It has a round tenon at it right ventricle. Pus welled up through the perforated car- low follower operated by a lever. The end of the case being tilage, and loose in an abscess holding an ounce or more of tied, the case is readily turned, and the operation completed. duced at one operation, and therefore combines the functions of both bit and reamer. The drill has acute angled points or side cutters and a concave cutting edge extending transersely between said points.

\section{How America Crowds England}

In giving his impressions of America in a leading. English periodical, a recent English visitor remarks that the RussoTurkish war ought to have shown the American manufacthers that they have little reason to fear the English. So ar as he had been able to learn not a single cartridge had een made in Birmingham for either Russia or Turkey; but when he was in Bridgeport, the cartridge factories had been unning day and night for months, and he saw a Russian nd a Turkish commissioner in the same works. The fact was the Americans had made the rifles as well as the caridges for both combatants. As further evidence of the threatened supremacy of American manufacturers he noted the fact that Lowell was sending cotton cloths to Manchester, and that in our retail stores cotton goods were marked at a lower price than that at which goods of the same quality could be sold at Liverpool or London. "It is the same," he idd "with the other manufacturing industries of America. The manufacturers of hardware are beating us in market fter market from Hamburg to Melbourne. In Birmingham itself the merchants are importing from the United States such articles as axes, hay forks, and agricultural implements f nearly every description, sash pulleys, and small castings of very many kinds, although it is estimated that freight and other expenses add 17 or 18 per cent to the cost of the goods." 